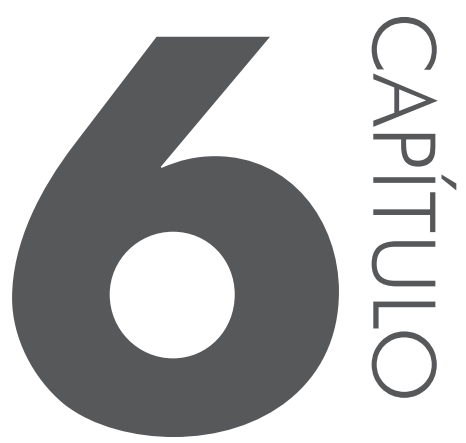

\title{
MODO DE SER E DE VIVER: AS ESTRATÉGIAS DE REPRODUÇÃO CAMPONESA NA COMUNIDADE RIBEIRÃO EM CATALÃO-GO
}

Marcelo do Nascimento Rosa José Henrique Rodrigues Stacciarini

Resumo: O artigo ora proposto tem como motivação a necessidade de reforçar, no debate acadêmico, a questão da transformação do território e explicitar as estratégias e as especificidades camponesas que permitem a sua sobrevivência e a permanência na terra. Portanto, tem como objetivo compreender o modo de ser e de viver dos camponeses na Comunidade Rural Ribeirão, localizada no município de Catalão-GO. A partir do trabalho familiar na terra, os camponeses estabelecem uma teia de relações sociais que se configuram numa especificidade 
diante das relações capitalistas de produção. Nesse sentido, parte-se do diário de campo, da vivência com as famílias camponesas e de reflexões teóricas para compreender as estratégias que os camponeses desenvolvem para permanecer na terra de trabalho. Dessa forma, é a partir das práticas exercidas pelos sujeitos da terra e suas estratégias de reprodução, existentes na contradição do modo capitalista de produção que permite em seu cerne relações capitalistas de produção e relações não capitalistas de produção, que confirmam a existência camponesa e sua especificidade de ser e de viver capaz de condicionar sua reprodução social.

Palavras-chave: Campesinato. Estratégias de reprodução. Comunidade Ribeirão.

Abstract: The article proposed here is motivated by the need to strengthen the academic debate, the issue of transformation of the territory and explain the strategies and peasant specifics that allow their survival and to remain on earth. Therefore, it aims to understand the way of being and living of the peasants in the Rural Community Ribeirão, in the municipality of Catalão-GO. From the family work the land the peasants establish a web of social relations that are configured in a specificity on the capitalist relations of production. In this sense, it is part of the diary, the experience with the peasant and theoretical reflections families to understand the strategies that farmers develop to stay in the land of work. Thus, it is from the practices exercised by the subjects of the land and its existing reproductive strategies in contradiction of the capitalist mode of production that allows at its core, capitalist relations of production and production of non-capitalist relations confirming the peasant existence and specificity to be and to live able to condition their social reproduction.

Keywords: Peasantry. Reproduction strategie. Community Ribeirão.

\section{INTRODUC̣ÃO}

Mesmo que aqui se trate da introdução de um artigo científico do qual se espera a total ausência de qualquer traço de subjetividade, conforme os paradigmas positivistas, é necessário esclarecer que o estudo que ora se propõe é fruto de vivência e militância no Movimento Camponês Popular ao lado das comunidades e das famílias camponesas.

Este artigo tem como motivação a necessidade de reforçar no debate acadêmico a questão da transformação do território e de explicitar as estratégias e as especificidades camponesas que permitem a sua sobrevivência e a sua permanência na terra.

O convívio quase que cotidiano com as famílias camponesas da comunidade Ribeirão no município de Catalão-GO me colocou no epicentro do processo de estratégia, resistência e luta pela permanência na terra. $\mathrm{O}$ artigo aqui proposto 
não carecerá de primeiros contatos, mas de uma retomada da continuidade de uma relação já estabelecida seja pela ciência geográfica, seja pela ação política realizada no Movimento Camponês Popular (MCP) diante da Comunidade.

Este pesquisador faz parte do Núcleo de Pesquisa Geografia, Trabalho e Movimentos Sociais (GETeM) e vem juntamente com demais membros participando de diversos debates e discussões sobre a temática do campesinato, os quais tem nos permitido analisar os vários conflitos gerado a partir das disputas por terra.

O artigo buscará enfocar o processo sócio-histórico, independente de velhos ou novos fatos, mesmo porque são eles que produzem a realidade geográfica. $\mathrm{O}$ que se almeja é evidenciar as ações concretas de homens e mulheres, no sentido de aclarar as relações sociais de sujeitos sociais reais, sem aplicar pressupostos morais ou apontar correntes políticas, mas manter uma coerência de classe sem perder o rigor teórico.

Nesse sentido, tem como objetivo compreender o modo de ser e de viver dos camponeses na Comunidade Rural Ribeirão, localizada no município de Catalão-GO. A partir do trabalho familiar na terra os camponeses estabelecem uma teia de relações sociais que se configuram numa especificidade diante das relações capitalistas de produção. A divisão do trabalho no cultivo da terra, do quintal e dos animais, bem como a lida da casa, o processo coletivo de tomada de decisões, a socialização do fruto do trabalho e a solidariedade estabelecida entre as diversas famílias que compõem a comunidade caracterizam o uso que esses sujeitos fazem do território, qual seja, a terra de trabalho como condição da reprodução social.

Contudo, há de se ressaltar que é a partir da luta social e política pelos seus interesses que os camponeses desta comunidade organizados no Movimento Camponês Popular (MCP) conseguem visualizar seu modo de ser e de viver como condição para sua autonomia, com potencialidade econômica, política e ideológica, perante as relações capitalista de produção. As famílias da comunidade que estão envolvidas em alguma forma de ação política compreendem o processo de exploração e buscam na diversificação da produção agrícola, não agrícola e nas políticas públicas uma estratégia para assegurar a renda oriunda do trabalho na terra. Dessa forma, é a partir das práticas exercidas pelos sujeitos da terra e suas estratégias de reprodução existentes na contradição do modo capitalista de produção - que permite, em seu cerne, relações capitalistas de produção e relações não-capitalistas de produção - que confirmam a existência camponesa e sua especificidade de ser e de viver capazes de condicionar sua reprodução social. É por meio de levantamento bibliográfico sobre o campesinato no modo capitalista de produção e de vivência com as famílias camponesas que se fundamentou a produção deste artigo. 


\section{OS CAMPONESES NO MODO CAPITALISTA DE PRODUC̣ÃO}

A compreensão da existência e da vida camponesa na atualidade exigem um olhar atento às transformações capitalistas ocorridas no campo no final do século XX e início do século XXI e às interferências que as mudanças ocorridas nesse período têm provocado no território camponês. Nesse sentido, o campesinato como parte da sociedade capitalista apresenta novas facetas econômicas, sociais e culturais que, longe de representar uma "descamponização", tece novas e diferentes estratégias de trabalho e produção, regidas pela luta política (NASCIMENTO ROSA; STACCIARINI, 2014).

Esse fato tem sido questionado por muitos estudiosos que não concebem a capacidade dessa população de se reproduzir socialmente. Contudo, nesse artigo, parte-se da compreensão de que o campesinato está inserido no modo capitalista de produção, reproduzindo-se pela contradição do capital ou por meio da luta pela terra oriunda dos movimentos sociais (NASCIMENTO ROSA; STACCIARINI, 2014). Entre os autores que defendem essa tese, encontramos Oliveira (1991, 1995 e 2004) e Martins (1991, 1995), dentre tantos outros.

Oliveira (1991) defende que a permanência dos camponeses na sociedade capitalista é resultado da própria contradição do capital. Assim, compreende-se o camponês como uma classe social dentro da sociedade capitalista e não fora dela. Ao mesmo tempo que o capitalismo entra no campo expropriando e explorando o camponês, também gera e/ou fortalece territórios sob o domínio camponês. Mesmo quando expulso de sua terra, o camponês sai em busca de terra em outro lugar, onde possa se reproduzir como camponês, agitando contraditoriamente as expectativas do capital, gerando um processo de desterritorialização em um lugar e reterritorialização noutro (MARTINS, 1991).

A renda da terra está sujeita ao capital, entretanto, ensina Oliveira (1991, p. 20):

O que podemos concluir desse desenvolvimento desigual e contraditório do capitalismo, particularmente no campo, é que estamos diante da sujeição da renda da terra ao capital. O que significa dizer que o capital não expande de forma absoluta o trabalho assalariado, sua relação de trabalho típica, por todo canto e lugar, destruindo de forma total e absoluta o trabalho familiar camponês.

Sendo assim, o capitalismo ao entrar no campo, gerando desigualdades e expropriação, contraditoriamente não expande as relações capitalistas por todo o espaço agrário, mas promove o "desenvolvimento desigual e contraditório do capitalismo" (SMITH, 1988), e se torna responsável pela permanência e recriação do campesinato. Assim, Oliveira (1991) afirma que à medida que avança a propriedade capitalista no campo, avança também a propriedade camponesa. Tendo 
a terra duas formas de apropriação: a capitalista e a camponesa. Enquanto na apropriação capitalista, a terra constitui-se em objeto de negócio, seja pelo fato de consistir em instrumento de exploração do trabalho alheio, logo extração de mais-valia, seja pelo fato de se manter como instrumento de especulação, reserva de valor. A apropriação camponesa, por sua vez, constitui a terra como terra de trabalho, estando a exploração restrita ao trabalho da família e configurando-a como instrumento de sobrevivência. Para Martins (1991):

A propriedade familiar não é a propriedade que explora o trabalho de outrem; é propriedade direta de instrumento de trabalho por parte de quem trabalha. Não é propriedade capitalista, é propriedade do trabalhador. Seus resultados sociais são completamente distintos, porque neste caso a produção e reprodução das condições de vida dos trabalhadores não são reguladas pela necessidade de lucro do capital, porque não se trata de capital no sentido capitalista da palavra. O trabalhador e o lavrador não recebem lucro. Seus ganhos são ganhos de seu trabalho e do trabalho de sua família e não são ganhos de capital, exatamente porque esses ganhos não provêm da exploração de um capitalista sobre um trabalho expropriado dos instrumentos de trabalho (MARTINS, 1991, p. 54).

Esse mecanismo analisado pelo autor evidencia a reprodução simples, cujo princípio é M - D - M (Mercadoria - Dinheiro - Mercadoria), ou seja, a produção de mercadorias objetiva a obtenção de dinheiro para a aquisição de mercadorias que não são produzidas, mas que são necessárias à reprodução da família.

Sendo assim, a permanência da propriedade camponesa questiona a tese da generalização do trabalho e da produção capitalista no campo. Apesar de a agricultura camponesa sofrer alterações e modificações dado aos contratos e parcerias que os camponeses estabelecem com empresários capitalistas no âmbito da circulação, cuja tendência é subordiná-los aos interesses capitalistas, pode-se observar na Comunidade Ribeirão, no município de Catalão-GO, que está presente uma racionalidade cuja centralidade é a reprodução social da família, alicerçada na terra de trabalho.

Nota-se uma lógica camponesa que se desenha em diferentes estratégias de trabalho e renda ao longo do tempo, mas que é distinta daquela que move as empresas capitalistas que têm como centralidade a obtenção do lucro. E isso não quer dizer que a reprodução social da família camponesa se restrinja à subsistência. O que está em consideração neste caso é a melhoria crescente e continuada da qualidade da vida e do trabalho camponês, melhoria essa que contempla outras dimensões além da renda porventura obtida (CARVALHO, 2010).

Em meio à tese da homogeneização das relações de trabalho no campo, o trabalho e o modo de vida camponeses apresentam uma dinâmica territorial, social e produtiva singular que sofre alterações ao longo do tempo para manter uma constante: permanecer na terra de trabalho com a família. 


\subsection{Os camponeses no modo capitalista de produção}

"O campesinato contemporâneo é uma realidade que envolve milhões de famílias no Brasil e no mundo [...]" (CARVALHO, 2010, p. 2). Ele trás em si, apesar da violenta expansão capitalista no campo, uma identidade social de resistência ${ }^{1}$ capaz de negar as relações de dominação e exploração entre homens e natureza apresentadas como hegemônicas pelo capitalismo.

Contudo, ao se afirmar a existência do camponês como contradição e, por vezes, negação das relações capitalistas em uma sociedade na qual domina o modo capitalista de produção, tem-se que considerar as ponderações de Paulino (2006) de que:

Não se trata de negar a interferência das forças hegemônicas capitaneadas pelo Estado no modo de vida camponês, mas de apontar que a existência dessa classe não pode ser explicada na perspectiva de que seria uma "licença" capitalista, pois, no limite, os camponeses poderiam sobreviver fora do circuito mercantil [capitalista], tendo em vista a sua capacidade de produzir seus próprios meios de vida (PAULINO, 2006, p. 318).

Essa possível autonomia camponesa dada pelo fato das famílias camponesas terem posse do meio de produção, qual seja, a terra; sofre interferências de natureza econômica, política e ideológica que tendem à homogeneização da racionalidade capitalista.

A contradição entre as empresas capitalistas do agronegócio e os camponeses, diferentemente do que se verifica na relação social de assalariamento, não está no interior do processo de trabalho, ela se efetiva na “[...] transferência de renda da unidade de produção camponesa para as empresas do agronegócio durante as relações comerciais, pelo processo de exploração dos camponeses [...] pelos capitalistas quando se efetuam contratos de produção entre eles através da chamada integração". (CARVALHO, 2010, p. 5). Paulino (2006) chama esse processo de monopolização do território pelo capital e descreve que ele acontece quando "a produção propriamente dita se dá no interior de relações não tipicamente capitalistas, em que os trabalhadores não estão despojados dos meios de produção" (PAULINO, 2006, p. 103), ou seja, o capitalismo, ao não ter o poder de reproduzir integralmente as relações de trabalho e produção de acordo com sua lógica, torna-as funcional à sua reprodução. Mantém os camponeses de posse da terra com o seu trabalho familiar, mas os explora ao subjugar a renda da terra.

1 Categoria adotada por Castells (1999) ao analisar os desdobramentos que as ações e as lutas sociais proporcionam à identidade de camponeses e trabalhadores. 
Isso é totalmente passível de explicação ao se considerar que a produção do capital não é resultado das relações capitalistas de produção, como ensina Oliveira (1986): “[...] o desenvolvimento do modo capitalista de produção supõe, na sua essência, a necessidade de criar, de fazer nascer, os capitalistas, a sua base social. [...] a ampliação da classe burguesa não se faz apenas pela hereditariedade dos capitalistas, mas, sobretudo, no processo de produção do capital” (OLIVEIRA, 1986, p. 26).

Nesse sentido, a acumulação primitiva é parte integrante e continuada da contraditória reprodução do capital, pois os capitalistas estão envolvidos na reprodução do capital, por meio da extração de mais-valia do trabalho assalariado e da produção do capital, com a sujeição da renda da terra. E como ainda retrata Paulino (2006, p. 109) é por meio da sujeição da renda da terra que os capitalistas metamorfoseiam relações camponesas (não capitalistas) em capital.

No caso camponês, a renda da terra é gerada pelo trabalho familiar e está contida nos produtos que os camponeses colocam no mercado e interessa aos capitalistas se apropriarem dessa renda da terra. Sabendo que só o trabalho é capaz de gerar valor, os capitalistas, ao comprarem a produção camponesa por um preço inferior ao valor de trabalho nele contido, se apropriam do trabalho camponês; tirando seu principal instrumento de autonomia.

Assim, a produção do capital não pressupõe a imediata sujeição do trabalho ao capital, mas a apropriação do produto do trabalho. Martins (1995) explica que: "Na medida em que o produtor preserva a propriedade da terra e nela trabalha sem o recurso do trabalho assalariado, utilizando unicamente o seu trabalho e o de sua família, ao mesmo tempo em que cresce a sua dependência em relação ao capital [...] estamos diante da sujeição da renda da terra ao capital" (MARTINS, 1995, p. 175).

A transformação da renda da terra em taxa de lucro para a indústria e/ ou empresas do agronegócio está na quantia de trabalho não pago contido nas matérias-primas ou alimentos adquiridos dos camponeses. Todavia, vale ressaltar que há outras esferas no circuito capitalista de se apropriar da renda da terra, tais como: a intermediação do capital comercial, o mecanismo de preços estabelecidos pelas indústrias de insumos e máquinas, entre outras situações em que ocorre a transferência de renda. E, ao permitirem a transferência da renda da terra, os camponeses se tornam funcional ao modo capitalista de produção, se subordinando ao sistema.

Contudo, a contradição é inerente ao capitalismo. A partir das mesmas ferramentas (posse da terra e trabalho familiar), os camponeses têm um potencial projeto social estratégico de construir a autonomia camponesa garantindo a apropriação da renda da terra por eles gerada e negando a lógica capitalista de produção e reprodução do capital. Na diversificação da produção existe uma maneira de se proteger das formas predatórias de extração de renda e, por isso, 
não é incomum observar em comunidade com domínio camponês a variedade de cultivos, criações e demais atividades. Essa tática proporciona aos camponeses uma menor vulnerabilidade e uma maior possibilidade de eles se apropriarem da renda da terra. Essa tática, aliada à eliminação dos intermediários na comercialização da sua produção, costura a estratégia de construírem a autonomia e garantirem a permanência e reprodução camponesa.

\subsection{A estratégia de reprodução camponesa na Comunidade Ribeirão}

A Comunidade Ribeirão, situada no município de Catalão-GO, a aproximadamente $10 \mathrm{~km}$ da sede municipal (ver Figura 1), conta com cerca de 119 moradores. ${ }^{2}$.A unidade camponesa na Comunidade Ribeirão, no município de Catalão-GO, se materializa por meio da família, do trabalho e da terra. A família é central e é por meio dela que se constituem as relações de parentesco e de vizinhança, exemplificadas pelas trocas de alimentos e pelos dias de trabalhos na roça.

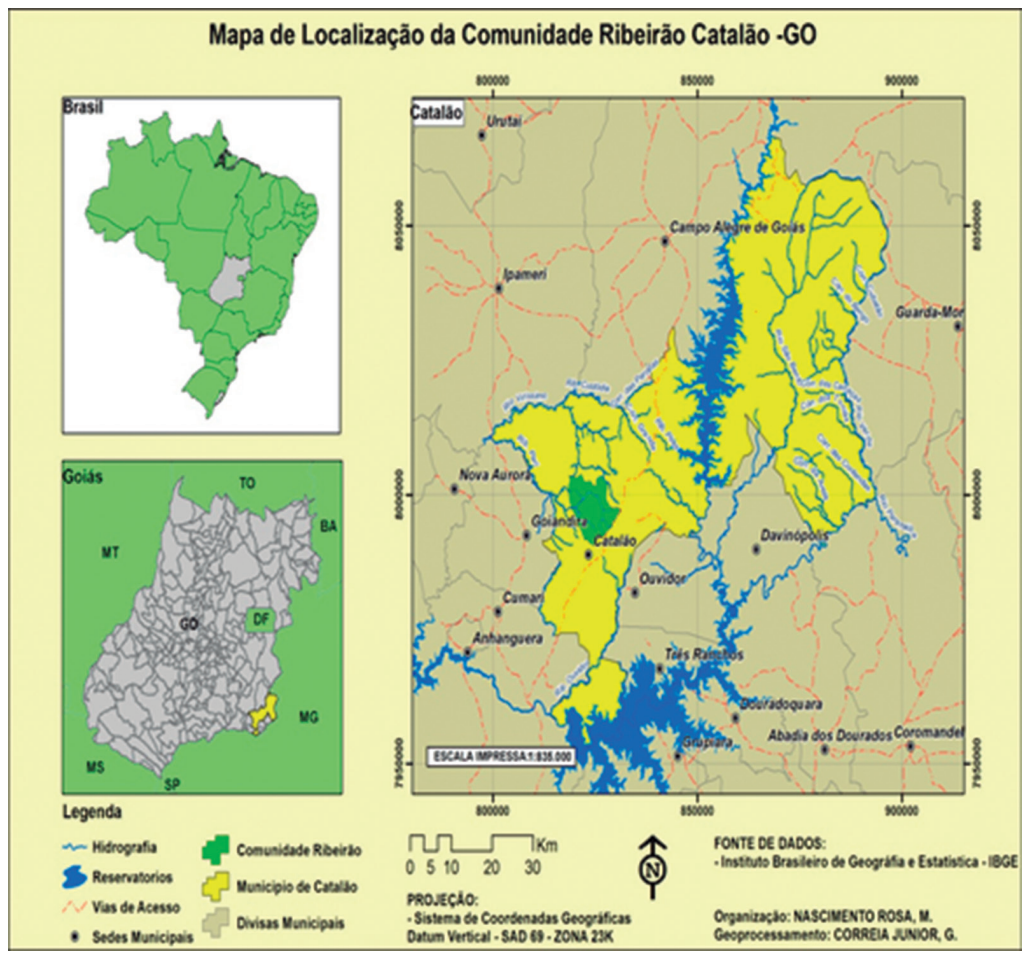

Figura 1. Mapa da localização da Comunidade Ribeirão, no município de Catalão-G0.

2 Segundo pesquisa publicada por Guimarães (2010). 
A produção camponesa é um dos elementos que conduz a dinâmica do território familiar e comunitário e cria o território camponês na imagem da Comunidade.

Os camponeses da Comunidade Ribeirão se autodenominam como pequenos produtores. São trabalhadores que adquiriram a posse da terra por herança e possuem laços de parentesco e vizinhança que lhes propiciaram estabelecer uma identidade como camponeses no lugar. Organizam seu trabalho e sua produção de forma a não sujeitarem sua renda às personae do capital para, dessa forma, garantirem sua autonomia. Martins (1991) retrata o momento da perda da autonomia camponesa:

Apenas quando o capital subordina o pequeno lavrador, controlando o mecanismo de financiamento e comercialização, [...], é que sub-repticiamente as condições de existência do lavrador e de sua família, suas necessidades e possibilidades econômicas e sociais, começam a ser reguladas e controladas pelo capital, como se o próprio lavrador não fosse o proprietário da terra, como se fosse um assalariado do capitalista (MARTINS, 1991, p. 59-60).

Sendo assim, é possível sugerir que a afirmação da autonomia relativa do campesinato contemporâneo perante o capital constitui a sua estratégia de reprodução social. A estratégia das famílias camponesas para permanecerem na terra é negar o que as nega, ou seja, negar a produção e reprodução ampliada do capital pela negação da racionalidade capitalista no campo.

A apropriação da renda da terra obtida a partir do trabalho da família é a garantia das condições para a permanência na terra e só é possível na medida em que não ocorra a transferência dessa renda a setores capitalistas. Nessa lógica, pode-se compreender porque as famílias camponesas da Comunidade Ribeirão, no município de Catalão-GO, vêm apostando em instrumentos de comercialização direta, como as feiras camponesas e mercados institucionais como o Programa Nacional de Merenda Escolar (PNAE), pois esses negam a exploração da renda da terra realizada pelo mercado capitalista.

A reprodução camponesa na Comunidade Ribeirão é caracterizada por sua interação parcial com o mercado capitalista (compra de insumos, entre outros), mas com relativa autonomia no processo de comercialização, formando um território específico nos elementos (família, trabalho e a terra) que constituem a vida camponesa.

Aqui é importante enfocar que a vida camponesa não se limita na busca pela renda familiar que é a principal responsável pela melhoria crescente e continuada da qualidade de vida e do trabalho camponês. Os camponeses necessitam da garantia de outras dimensões como a relação de convivência com a natureza, a identidade de pertencimento ao local de reprodução da vida familiar, ao local de 
trabalho e à vida comunitária. Todas essas dimensões juntas é que caracterizam um território camponês, enquanto espaço de controle e de poder da apropriação social da natureza. ${ }^{3}$

Ao identificar os agentes da sujeição da renda como os intermediários (atravessadores) e a própria cooperativa de leite, as famílias camponesas da Comunidade Ribeirão desenvolveram diversas e diferentes formas e relações em seu território para garantir a apropriação da renda da terra. Isso não quer dizer que todas as iniciativas de produção e comercialização realizadas pelas famílias levaram-nas à conquista automática de sua autonomia perante o capital, até porque é o experimentar que rege a vida camponesa como Paulino (2006) retrata:

[...] ao me relatarem suas atuais estratégias produtivas, bem como as passadas, a palavra tentativa ocupou uma centralidade nos argumentos explicativos. Tentar é experimentar, mas só podem fazê-lo aqueles que detêm não apenas o controle sobre o seu tempo e seu espaço, mas, sobretudo, o controle sobre os processos que os envolvem, que emanam do conhecimento que alimenta a capacidade de inovação criativa (PAULINO, 2006, p. 317).

Neste contexto, o experimentar significa alcançar um determinado objetivo, que não é outro senão o controle do processo produtivo e da recriação social, e isso estabelece uma divergência com aqueles que defendem que a existência camponesa é algo dado ou definido por agente externo, qual seja, as personae do capital.

Todavia, há que se considerar fatores como as políticas públicas e as estratégias de ação dos movimentos sociais camponeses ao se avaliar a construção da autonomia camponesa e as possibilidades de reprodução, manutenção e expansão da agricultura camponesa como um projeto social estratégico.

$\mathrm{Na}$ análise do movimento concreto da realidade, Carvalho (2010) retrata que:

As políticas públicas, numa sociedade de classes, são sempre favoráveis e orgânicas aos interesses de classe das classes dominantes [...]. As políticas públicas direcionam a agricultura familiar ${ }^{4}$, ao serem orgânicos aos interesses de classe das classes dominantes no campo, induzem e submetem a reprodução social da agricultura campo-

3 Para Carvalho (2010, p. 10, grifo do autor) a "expressão apropriação social da natureza está compreendida como um processo político-ideológico de negação da 'apropriação privada da natureza' pelo capital".

4 Na conceituação dominante de 'agricultura familiar' está implícito o critério de gestão, em função da concepção de mundo dominante, pois a introdução das relações sociais de assalariamento na unidade de produção camponesa é uma exigência objetiva para o aumento da produção e da produtividade, tendo em vista que aceita-se como pertinente o modelo de produção e tecnológico da empresa capitalista. A reprodução dessa ideologia é aceita por amplas parcelas dos intelectuais e movimentos sociais e sindicais dos camponeses. 
nesa à racionalidade capitalista, não somente na emulação para a adoção do modelo de produção e tecnológico dominante e pela aceitação passiva da perda do controle familiar sobre os processos de trabalho da unidade de produção, mas, sobretudo, por intencionalmente negarem a presença efetiva de uma outra lógica de produção como a camponesa (CARVALHO, 2010, p. 3-4)

Os movimentos sociais e organizações sociais e sindicais camponesas, por distintos motivos históricos e políticos, ao se tornarem dependentes dos recursos governamentais para a manutenção e reprodução burocráticas das suas organizações se identificam com a lógica produtivista do capital, e aceitam as políticas públicas de integração dependente do campesinato ao capital como seu que-fazer político, na maior parte das vezes sem uma perspectiva estratégica de negação do modo capitalista de produção (CARVALHO, 2010, p. 13).

Corroborando com as análises de Carvalho (2010) é intuito dessa pesquisa (em andamento) analisar como as políticas públicas e as ações do movimento social camponês presentes na Comunidade Ribeirão contribuem para a construção da autonomia camponesa. Contudo, o que se verifica é que tais fatores não seguem um movimento unidirecional, nos quais as determinações hegemônicas se materializam na forma pura, segundo os idealizadores da classe dominante; até porque há uma apropriação e um processo de experimentar por parte das famílias camponesas.

A feira camponesa proposta pelo Movimento Camponês Popular (MCP) e a comercialização junto ao Programa Nacional de Merenda Escolar (PNAE) estão sendo experimentadas pelas famílias camponesas da Comunidade Ribeirão e apontadas como um importante instrumento de assegurar a renda da terra.

Esse experimentar é caracterizado pela autonomia que conduz os camponeses da Comunidade Ribeirão e seu território. Eles organizam seu trabalho e a sua produção de forma a garantir a produção e apropriação da renda e, dessa forma, sua permanência e reprodução na terra de trabalho.

\section{CONSIDERAÇÕES FINAIS}

A expansão do capitalismo no campo tem provocado profundas transformações nas relações sociais de produção e de trabalho, a ponto de suscitar interpretações que anunciaram o desaparecimento dos sujeitos que têm a terra como terra de trabalho: os camponeses. Entretanto, verifica-se que, ao contrário, os camponeses têm se recriado no movimento de luta pela terra e de luta na terra, por meio de diferentes estratégias que possibilitam sua existência.

Assim, compreende-se o camponês como uma classe social de dentro da sociedade capitalista e não de fora dela. Para Oliveira (1991) a permanência dos camponeses na sociedade capitalista é resultado do desenvolvimento desigual e contraditório do capitalismo. 
No caso dos camponeses que já têm a posse da terra e que nela trabalham, como as famílias camponesas da Comunidade Ribeirão, no município de Catalão-GO, constata-se a existência de uma gama de experiências que não significou e não significa apenas uma mudança de atividades ao longo dos anos, mas, o desenvolvimento de relações sociais de produção e de trabalho que vêm garantindo, contraditoriamente, uma relativa autonomia frente às relações capitalistas. Essas relações singulares mantêm uma lógica de ser e de viver responsáveis pela permanência na e pela preservação da identidade camponesa.

Essa forma de resistência demonstra uma reação camponesa que não aceita a expropriação como condição predestinada e busca na contradição do modo capitalista de produção estratégias para continuar se reproduzindo.

Desde a divisão de tarefas entre os membros da família camponesa até a ação política nos movimentos sociais, o objetivo é assegurar a renda da terra e do trabalho bem como o modo de produzir e viver. A luta pela autonomia, mesmo que relativa, perante as relações capitalistas, produz diversas territorialidades potenciais e alternativas ao agronegócio, as quais ainda não foram consideradas adequadamente pela academia.

No trabalho de campo realizado na Comunidade Ribeirão pôde-se observar que é incomum a dedicação exclusiva a apenas uma atividade, de modo que os membros da família dividem seu tempo entre diversas tarefas e em diferentes sistemas produtivos, regidos por um calendário sazonal. A estratégia de diversificar e disponibilizar diferentes produtos, como milho, cana, feijão, arroz, hortaliças, pequenos animais (frango, suínos, etc.), leite, queijo, requeijão etc. faz com que os camponeses sempre tenham outros produtos para garantir sua renda e sua autonomia.

Nesse sentido, não se pode deixar de ressaltar que é a partir da luta social e política pelos seus interesses que os camponeses desta comunidade organizados no Movimento Camponês Popular (MCP) conseguem visualizar seu modo de ser $e$ de viver como condição para sua autonomia, com potencialidade econômica, política e ideológica, perante as relações capitalistas de produção,.

Assim, a tese da busca da autonomia camponesa como estratégia de reprodução social está distante de qualquer ideia de um campesinato que vive na redoma do autossustento. O campesinato não pode ser pensado como sujeito isolado do mundo, mas deve ser visto como uma classe social que vive inserida na sociedade capitalista, sem, no entanto, realizar um trabalho alienado.

Em meio à leitura de hegemonização das relações de produção e de trabalho no campo, a produção e o trabalho camponês apresentam uma dinâmica territorial, social, política e produtiva singular que merece ser investigada pela perspectiva emancipatória desses sujeitos que teimam em (re)existir. 


\section{REFERÊNCIAS}

ABRAMOVAY, R. Paradigmas do capitalismo agrário em questão. São Paulo: Hucitec; Edunicamp, 1992.

ASFRAGO. História do crédito rural na agricultura familiar. Brasília, 2010. Disponível em: <http://www.asfagro.org.br>. Acesso em: 12 jun. 2012.

ASSOCIAÇÃO BRASILEIRA DE NORMAS TÉCNICAS. NBR 6023: informações e documentação: referências: elaboração. Rio de Janeiro, 2002.

CARVALHO, H. M. O campesinato do século XXI: possibilidades e condicionantes do desenvolvimento do campesinato no Brasil. Petrópolis: Vozes, 2005.

. De produtor rural familiar a camponês: a catarse necessária. Curitiba, 2009.

Disponível em: <http://www4.fct.unesp.br/nera>. Acesso em: 25 jun. 2012.

. Na sombra da imaginação: o camponês e a superação de um destino. Curitiba, 2010. Disponível em: <http://www.mcpbrasil.org.br/biblioteca/agricultura-camponesa>. Acesso em: 22 jun. 2012.

O campesinato contemporâneo como modo de produção e como classe social. Curitiba, 2012. Disponível no site: <http:www.mcpbrasil.org.br>. Acesso em: 21 abr. 2012.

CHAYANOV, A. V. La organización de la unidad económica campesina. Tradução Rosa María Russovich. Buenos Aires: Nueva Visión, 1974.

GRZYBOWSKI, C. Caminhos e descaminhos dos movimentos sociais no campo. 2. ed. Petrópolis: Vozes, 1990.

HARVEY, D. O novo imperialismo. Tradução Adail Sobral e Maria Stela Gonçalvez. 2. ed. São Paulo: Loyola, 2005.

MARTINS, J. S. O cativeiro da terra. São Paulo: Ciências Humanas, 1979.

Expropriação \& violência. a questão política no campo. São Paulo: Hucitec, 1991.

. Caminhada no chão da noite.São Paulo: Hucitec, 1989.

. Os camponeses e a política no Brasil. 5. ed. Petrópolis: Vozes, 1995.

. A chegada do estranho. São Paulo: Hucitec, 1993.

KAUTSKY, K. A questão agrária. 3. ed. São Paulo: Proposta, 1980.

LUXEMBURGO, R. A acumulação do capital. 2. ed. Rio de Janeiro: Zahar, 1976.

MARTINS, J. S. Camponeses e a política no Brasil. 5. ed. Petrópolis: Vozes, 1995. 1991.

. Expropriação \& violência - A questão política no campo. São Paulo: Hucitec,

MARX, K. O Capital. Rio de Janeiro: Civilização Brasileira, 1974. Livro 3. v. 4, 5 e 6.

NASCIMENTO, A. C.; MENDONÇA, M. R. Campesinato: uma existência contraditória no modo capitalista de produção. In: COLÓQUIO INTERNACIONAL MARX E ENGELS CAMPESINATO, 7., 2012, Campinas. Anais... Campinas: Centro de Estudos Marxistas, 2012. não paginado. 
MENDONÇA, M. R.A urdidura espacial do capital e do trabalho no cerrado do sudeste goiano. Tese (Doutorado em Geografia) - Faculdade de Ciências e Tecnologia de Presidente Prudente, Universidade Estadual Paulista, Presidente Prudente, 2004.

MESQUITA, H. A. de A modernização da agricultura: um caso em Catalão-Goiás. 1993. 180 f. Dissertação (Mestrado em História das Sociedades Agrárias) - Universidade Federal de

Goiás, Instituto de Ciências Humanas e Letras, Goiânia, 1993.

. Corumbiara: o massacre dos camponeses de Rondônia. 2001. 286 f. Tese

(Doutorado) - Faculdade de Filosofia, Letras e Ciências Humanas, Universidade de São Paulo, São Paulo, 2001.

OLIVEIRA, A. U. de. Modo capitalista de produção e agricultura. 2. ed. São Paulo: Ática, 1986.

. A agricultura camponesa no Brasil. São Paulo: Contexto, 1991.

. Geografia e território: desenvolvimento e contradições na agricultura. In:

ENCONTRO NACIONAL DE GEOGRAFIA AGRÁRIA, 12., 1995, Rio Claro. Anais... Rio Claro: AGETEO, 1995.

. Geografia Agrária: perspectivas no início do Século XXI. In: OLIVEIRA, A. U. de; MARQUES, M. I. M. (Org.). O campo no século XXI: território de vida, de luta e de construção da justiça social. São Paulo: Casa Amarela; Paz e Terra, p. 27-64, 2004. 2007. Modo capitalista de produção, agricultura e reforma agrária. São Paulo: Labur, Agricultura e indústria no Brasil. Campo-Território: revista de geografia agrária, v. 5 , n. 10 , p. 5-64, ago. 2010.

NASCIMENTO ROSA, M. do; STACCIARINI, J. H. R. Os camponeses: uma leitura necessária. In: CONGRESSO BRASILEIRO DE GEÓGRAFOS, 7., 2014, Vitória. Anais... Vitória: Associação dos Geógrafos Brasileiros, 2014. não paginado. <http://www.cbg2014.agb.org.br/resources/anais/1/1404387885_ARQUIVO_ TextoCompletoCBGOK.pdf>. Acesso em: 11 set. 2015.

PAULINO, E. T. Por uma geografia dos camponeses. São Paulo: UNESP, 2006. THOMAS JÚNIOR, A. As correntes teóricas na geografia agrária brasileira. Presidente Prudente, 2009. 